\title{
Prognostic phenotypic classification for canine mammary tumors
}

\author{
GIOVANNA ROSSI VARALLO ${ }^{1}$, GABRIELA BOTTARO GELALETI ${ }^{2}$, \\ LARISSA BAZELA MASCHIO-SIGNORINI ${ }^{2}$, MARINA GOBBE MOSCHETTA ${ }^{3}$, \\ JULIANA RAMOS LOPES ${ }^{2}$, ANDRIGO BARBOZA DE NARDI ${ }^{1}$, MIRELA TINUCCI-COSTA ${ }^{1}$, \\ RAFAEL MALAGOLI ROCHA ${ }^{4}$ and DEBORA APARECIDA PIRES DE CAMPOS ZUCCARI ${ }^{3}$
}

\author{
${ }^{1}$ Faculty of Agricultural and Veterinary Sciences, Universidade Estadual Paulista, Jaboticabal, São Paulo 14884-900; \\ ${ }^{2}$ Institute of Biosciences, Letters and Exact Sciences, Universidade Estadual Paulista, \\ São José do Rio Preto, São Paulo 15054-000; ${ }^{3}$ Laboratory of Molecular Investigation of Cancer, \\ Department of Molecular Biology, Faculty of Medicine of São José do Rio Preto, São José do Rio Preto, \\ São Paulo 15090-000; ${ }^{4}$ International Research Center-A.C. Camargo Cancer Center, São Paulo, São Paulo 01508-010, Brazil
}

Received July 3, 2018; Accepted July 9, 2019

DOI: $10.3892 / 01.2019 .11052$

\begin{abstract}
Mammary neoplasms are a heterogeneous form of disease, and in order to determine its course and biological features with more accuracy, investigations based on tumor phenotypes are required. The aim of the present study was to propose and validate a phenotypic classification for canine mammary tumors and to assess any association between clinicopathological characteristics, survival and prognosis. For the immunohistochemistry analysis, the primary antibodies against estrogen receptor- $\alpha$, progesterone receptor, human epidermal growth factor receptor 2 (HER-2)/neu and E-cadherin were used. A total of 110 canine mammary tumors were investigated; 42 tumors were classified as luminal A, 41 as luminal B, 17 as triple-negative and 10 as HER-2-positive. The luminal A and $\mathrm{B}$ phenotypes were associated with improved prognosis, whereas HER-2positive and triple-negative tumors were more aggressive, and exhibited a significant association with the occurrence of metastasis, a worse Tumor-Node-Metastasis classification and shorter survival time $(\mathrm{P}<0.05)$. In addition, there were different levels of E-cadherin expression intensity observed among the four tumor profiles investigated. Luminal $A$ and $B$ phenotypes presented an upregulation of E-cadherin compared with the HER-2 positive and triple-negative
\end{abstract}

Correspondence to: Mrs Debora Aparecida Pires de Campos Zuccari, Laboratory of Molecular Investigation of Cancer, Department of Molecular Biology, Faculty of Medicine of São José do Rio Preto, 5418 Brigadeiro Faria Lima Avenue, São José do Rio Preto, São Paulo 15090-000, Brazil

E-mail: debora.zuccari@famerp.br

Abbreviations: ER, estrogen receptor; HER-2, human epidermal growth factor receptor 2; PR, progesterone receptor; TNM, Tumor-Node-Metastasis

Key words: dogs, E-cadherin, mammary tumors, phenotypes, prognostic phenotypes $(\mathrm{P}<0.05)$. From the results of the present study, the proposed immunohistochemical panel and phenotypic classification techniques could be useful diagnostic tools with a good technical applicability in veterinary oncology. The analysis of E-cadherin expression in the panel of tumor markers allowed a more accurate classification for determining the biological features of the mammary tumor.

\section{Introduction}

Mammary tumors are the most common types of cancer affecting unspayed bitches or bitches that are spayed late in life (1-5). This disease represents $\sim 52 \%$ of all neoplasms affecting bitches, and $41-53 \%$ of mammary tumors are histopathologically diagnosed as malignant (1-7). Studies conducted in Brazil between 2010 and 2012 have demonstrated that the incidence rate of malignant mammary tumors ranges from $60-82 \%(8,9)$. Therefore, studying mammary neoplasms is of great importance due to the high rates of mortality and morbidity that affect this animal population $(10,11)$.

Clinical and histological prognostic factors for mammary tumors have been previously studied and have been suggested to be important parameters in determining the possible outcome and progression of the disease $(3,12)$. The most important clinical characteristics are tumor size, lymph node status and the presence of distant metastasis (13). However, they are still incipient and cannot be used as precise and reliable predictive and/or prognostic factors, particularly in the early stages of the disease (10).

Previous histological classifications for canine mammary tumors described in the literature failed to identify potential biological differences among histological subtypes, particularly in patients with the same disease status that have the same anatomical, morphological and grade histological structure (14-18). A number of researchers have suggested new histopathological classifications, or have made attempts to modify the existing ones, resulting in subjectivity during interpretation (14-18). In addition, due to many different 
classification systems, oncologists have found it difficult to select the one that best defines and characterizes the disease as well as its progression (10).

Cell phenotypes can be used as a new tool that contributes to the understanding of tumor biology (10), so cancer cell immunostaining should be emphasized as an effective tool in the clinical setting. A number of immunohistochemical markers have been proposed and a panel of markers has been already established for use in the clinical prognosis of women with breast cancer (19-21). Importantly, the analysis of this panel of markers can identify a specific phenotypic tumor profile, which is associated with a particular biological behavior $(22,23)$. This panel includes the estrogen receptor (ER) and progesterone hormone receptor (PR), human epidermal growth factor receptor 2 (HER-2)/neu oncogene, the cell proliferation marker Ki-67 and p53 (10). However, in veterinary medicine, there are few studies currently focusing on this subject and the published results are conflicting (24-26).

Therefore, the objective of molecular research in breast cancer, in addition to defining specific biological profiles, is to identify novel potential therapeutic targets in order to increase the control and the treatment of this disease. Previous findings have provided important prognostic and predictive information, as well as a better understanding of the complex molecular mechanisms underlying tumorigenesis $(22,27)$. As a result, different treatment approaches were optimized and thus, the ability to identify molecular subtypes has become an important element for the management of breast cancer (28).

By combining the protein expression of ERs, PRs and HER-2, three markers widely used in the diagnosis of breast cancer in women, it is possible to identify the luminal groups A, luminal B, HER-2-positive and triple-negative (22). This new form of classification has gained popularity and credit among the scientific community as it has been discovered that the groups are associated with specific treatments (29-31). The luminal group presents a favorable prognosis and responds to hormone therapy, whereas monoclonal therapy is indicated in the HER-2 group $(32,33)$. The targeted therapies against HER-2 positive tumors are very effective, both in the adjuvant and the metastatic setting $(34,35)$. Trastuzumab is a humanized monoclonal antibody that improves response rates, decreases the progression of the disease and improves survival time when used alone or added to chemotherapy in metastatic breast cancer (36). The triple-negative group has worse prognosis and requires specific treatments $(37,38)$. It is expected that patients with this profile will not benefit from the use of trastuzumab or hormonal therapies, which results in challenges when prescribing and administering treatments in patients with triple-negative mammary tumor $(39,40)$.

In addition, E-cadherin is considered an important prognostic immunohistochemical marker. This molecule is a cell adhesion protein and an important regulator of the epithelial phenotype. The low expression of E-cadherin is associated with the malignant progression of the disease (41), and the low expression of this protein occurs in processes involved in the epithelial-to-mesenchymal transition (EMT). EMT promotes the acquisition of mesenchymal characteristics in epithelial cancer cells with the invasion and spreading of cancer cells $(41,42)$. Canine mammary tumors have been observed to be significantly associated with the loss of E-cadherin expression, resulting in a poor prognosis (43).

Therefore, the purpose of the present study was to define a phenotypic immunohistochemical classification for canine mammary tumors in four groups: i) luminal $\mathrm{A}\left(\mathrm{ER}^{+}\right.$and/or $\mathrm{PR}^{+}$, and HER-2-); ii) luminal B (ER ${ }^{+}$and/or $\mathrm{PR}^{+}$, and $\mathrm{HER}-2^{+}$); iii) HER-2 positive (ER-, $\mathrm{PR}^{-}$and $\left.\mathrm{HER}-2^{+}\right)$; and iv) triple-negative (ER-, $\mathrm{PR}^{-}$and HER-2-). In addition, the present study investigated E-cadherin expression in these phenotypes in order to examine the association between tumor classification and prognosis also in the canine species.

\section{Materials and methods}

Experimental group. The experimental group consisted of 110 bitches, enrolled between January 2011 and December 2013, of different breeds and ages (3-15 years). In all dogs examined, the mammary cancer developed spontaneously. All patients were treated in the Obstetric and Reproduction Department of the Veterinary Hospital Governador Laudo Natel of Faculdade de Ciências Agrárias e Veterinárias/Universidade Estadual Paulista, Jaboticabal, Brazil, and the veterinary clinics of São José do Rio Preto (São Paulo, Brazil). The owners of each dog provided written consent for the use of the samples, and the present study was approved by the The Ethics Committee on Animal Experimentation of the Faculty of Medicine of São José do Rio Preto prior to the study start. All dogs were treated surgically, and none of the dogs received any additional anticancer treatment prior to or following mastectomy.

Following excision of the tumor, the patients were followed up for 1-18 months. During the follow-up time, the veterinarians evaluated tumor metastasis and recurrence, as well as the cause of mortality in the animals. For histopathological diagnosis, the tumor biopsies collected were classified according to Goldschmidt et al (18).

The parameters employed for the classification of clinical tumor staging were in accordance with the Tumor-Node-Metastasis (TNM) system established by the World Health Organization for canine mammary gland tumors $(44,45)$.

Immunohistochemistry (IHC). The IHC procedure was performed following the method described by Lopes et al (46). Tumor samples were embedded into paraffin blocks and cut into $3-\mu \mathrm{m}$ sections. The samples were prepared on silanized glass slides prior to deparaffinization. The sections were rehydrated in an ascending range of alcohol concentrations and incubated with $3 \%$ hydrogen peroxide for $30 \mathrm{~min}$. Antigen retrieval was performed by heating at $95^{\circ} \mathrm{C}$ in buffer for $35 \mathrm{~min}$. The slides were incubated with bovine serum albumin (BSA). The slides were incubated at $4^{\circ} \mathrm{C}$ overnight with the primary antibodies (Table I). After being washed with phosphate-buffered saline (PBS) for $15 \mathrm{~min}$, incubation was carried out with Starr Trek Universal HRP Detection kit (Medical Biocare, Concord, CA, USA), consisting of the secondary antibody 'anti-mouse, rabbit and goat immunoglobulin with biotin' for $1 \mathrm{~h}$ and 'streptoavidin complex with peroxidase' for $30 \mathrm{~min}$, followed by washes with PBS for 
$15 \mathrm{~min}$. Subsequently, $0.5 \%$ 3,3'-diaminobenzidine tetrahydrochloride was applied to the slides for $2-5 \mathrm{~min}$ at $20-22^{\circ} \mathrm{C}$. The slides were counterstained with Harris' hematoxylin for 40 min. Negative controls were obtained by omitting the primary antibody.

The slides were scanned using the Panoramic Digital Slide Scanner (magnification, x40; 3DHISTECH ${ }^{\circledR}$ ) and Panoramic Viewer software (3DHISTECH ${ }^{\circledR}$ ) (47).

Analysis and interpretation of IHC. For the ERs and PRs, the immunoreactivity index of Allred et al (48) was applied. The final score was calculated according to the quantity of marked cells and the intensity of the staining. The scores ranged between 0 and 8 . Samples with a score of $0-1$ were considered negative, and samples with a score of 2-8 were considered positive. The scores and criteria used to quantify the labeled cells were: i) 0 , no labeling; ii) 1 , labeling in $<1 \%$ of cells; iii) $2,1-10 \%$; $3,11-33 \%$; iv) $4,34-66 \%$; and $5,67-100 \%$. The criteria and scores used to determine the intensity of immunostaining were: i) Absent, 0; ii) weak, 1; iii) moderate, 2; and iv) strong, 3 . The staining intensity was determined by eye. The sum of these criteria for each sample determined the final score.

HER-2/neu exhibited membrane staining in $>10 \%$ of neoplastic cells, and the intensity of the staining was assessed according to a previously described semi-quantitative method (49). The criteria used for the score were as follows: i) 0 , no staining; ii) 1 , weak, incomplete membranous staining; iii) 2 , moderate, complete membranous staining in at least $10 \%$ of tumor cells; and iv) 3, strong membranous staining in at least $10 \%$ of tumor cells. The staining intensity was determined by eye. Cases with a score of $0-1$ were considered negative, whereas scores of 2-3 were considered to exhibit HER-2 positive.

Expression of E-cadherin was performed using the modified semi-quantitative immunoreactive score scale according to Remmele and Stegner (50). Immunostaining signal of E-cadherin was observed in the cytoplasmic membrane. The method described by Remmele and Stegner takes into account both the proportion of positively stained cells and the intensity of the staining. The criteria used to quantify the labeled cells were: i) 0 , no labeling; ii) 1 , labeling in $\leq 10 \%$ of cells; iii) $2,11-50 \%$; iv) $3,51-80 \%$; and v) $4,81-100 \%$. The criteria used to determine the intensity of immunostaining were: i) Zero, no staining; ii) '+', weak staining; iii) ' ++ ', moderate staining; and iv) ' +++ ', strong staining. The multiplication of the criteria for each sample determined the final score.

Statistical analysis. All statistical analyses were performed using GraphPad Prism (version 5.0; GraphPad Software, Inc.) software. Raw data were initially subjected to descriptive analyses to determine the normal distribution. Any associations between immunostaining intensity of E-cadherin and the mammary cancer phenotypes of the patients within each group were analyzed using the $\chi^{2}$ test. The survival curve was constructed using the Kaplan-Meier method and the differences between the curves were evaluated using a log-rank test and hazard function. $\mathrm{P}<0.05$ was considered to indicate a statistically significant result.

\section{Results}

Phenotype characterization. In the present study, the luminal A phenotype was the most frequently observed (38.2\%), followed by luminal B $(37.3 \%)$, triple-negative $(15.4 \%)$ and HER-2 positive (9.1\%). Fig. 1 presents the phenotypic profiles according to the immunohistochemical markers ER, PR and HER2. The mammary tumor group exhibited the most frequent histopathological classifications: i) Luminal A (29.0\% complex mammary carcinoma, $24.0 \%$ tubulopapillary mammary carcinoma and $21.0 \%$ mixed mammary carcinoma); and ii) luminal B (37.0\% complex mammary carcinoma, $19.0 \%$ tubulopapillary mammary carcinoma, $15.0 \%$ mixed mammary carcinoma and $15.0 \%$ solid carcinoma); iii) HER-2 positive (30.0\% complex mammary carcinoma, $30 \%$ tubulopapillary mammary carcinoma and $20.0 \%$ anaplastic mammary carcinoma); and iv) triple-negative $(29.4 \%$ complex mammary carcinoma, $23.5 \% \mathrm{mixed}$ mammary carcinoma and $23.5 \%$ tubulopapillary mammary carcinoma).

Mammary tumor phenotypes and clinicopathological characteristics. For the luminal A tumor subtype, only $14.3 \%$ $(6 / 42)$ of the animals presented cutaneous (2/42) and pulmonary (2/42) metastasis and recurrence (1/42). Regarding the TNM classification, the minority of mammary tumors were classified with the worst prognosis. Regarding the luminal B subtype, $22.0 \%(9 / 41)$ of the animals presented hepatic (2/41) and pulmonary (5/41) metastasis and recurrence $(5 / 41)$. For the TNM classification, stages I and II (30/41) were significantly higher in number compared with stages III, IV and V.

Regarding HER-2 positive, $80.0 \%$ (8/10) of animals presented cutaneous (1/10) and pulmonary (7/10) metastasis and $60.0 \%(6 / 10)$ exhibited stage III, IV or V TNM classification. In the triple-negative tumor phenotype, $76.4 \%(6 / 10)$ of animals presented hepatic (1/17) and pulmonary (12/17) metastasis and $53.0 \%(9 / 17)$ of tumors exhibited stage III, IV and V TNM classification.

Table II presents the distribution of frequency (number of cases) of clinicopathological characteristics in the phenotypes luminal A, luminal B, HER-2 positive and triple-negative mammary cancer in female dogs.

Association between mammary tumor phenotypes and survival. Regarding the luminal A subtype, only three patients (3/42) died as a result of the disease (pulmonary metastasis). The others (39/42) were examined during the 18 months of follow-up without experiencing recurrence. For the luminal B subtype, eight dogs (8/41) died due to distant metastasis (pulmonary or hepatic). In two patients $(2 / 41)$ there was a local tumor recurrence within the surgical scar. The other dogs (32/41) had no complications associated with the disease during the 18 months of follow-up. In the present study, it was observed that the majority of the patients classified as luminal A and luminal B were included in stage I of the disease and had longer survival times when compared with other phenotypes.

In the tumors with HER-2 positive, the mean survival time was 167 days. A total of seven dogs (7/10) died due to 


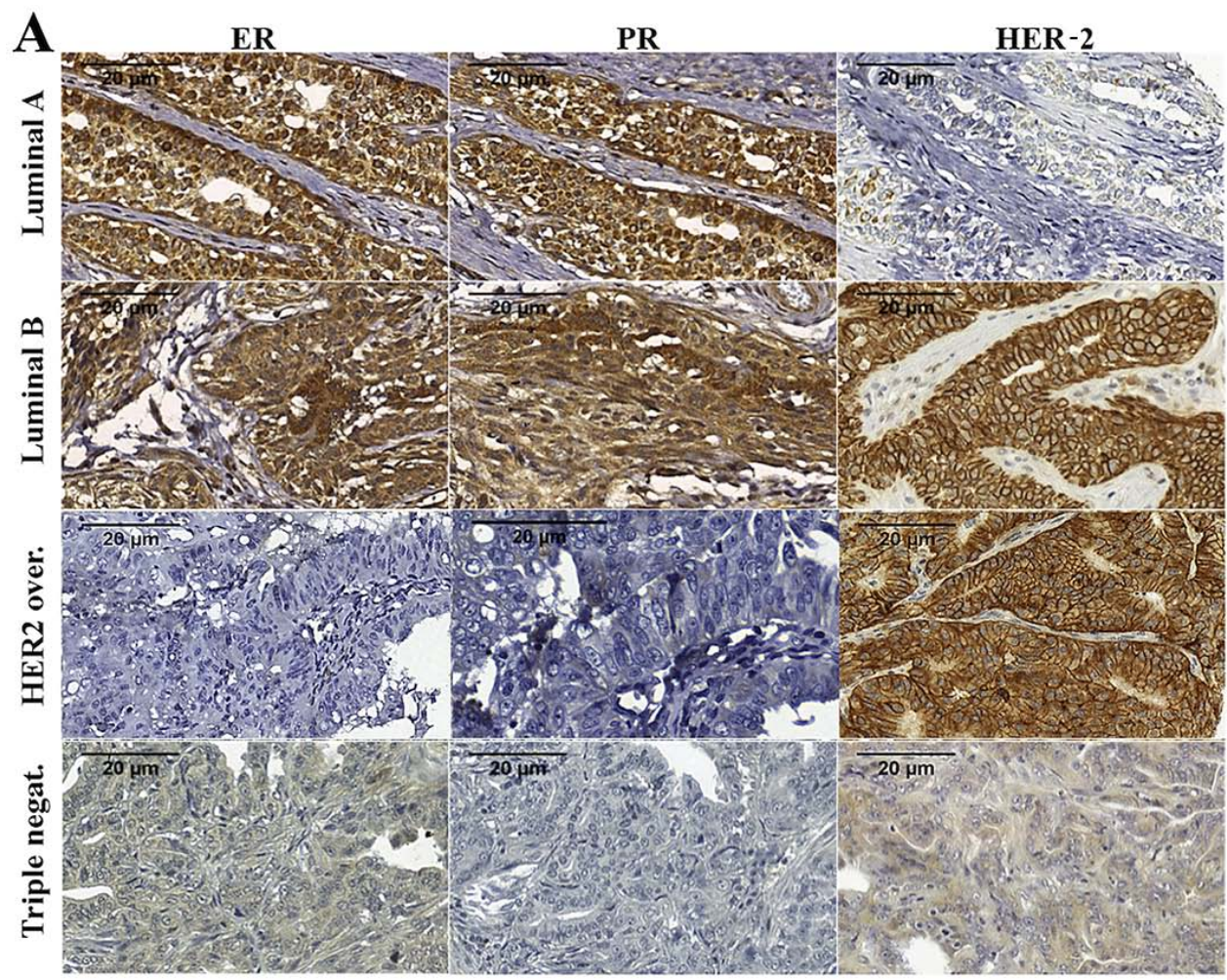

B ER; PR; HER-2; E-cad.
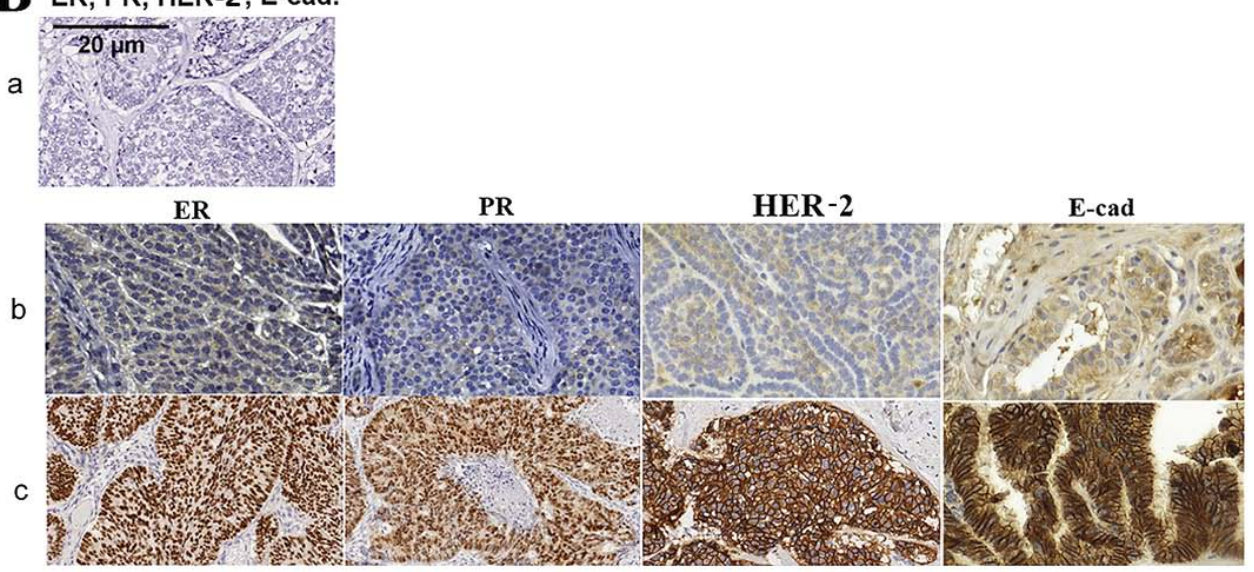

Figure 1. Immunohistochemical characteristics of mammary cancer phenotypes in bitches. (A) Photomicrograph of phenotypic profiles classified by immunohistochemical markers of ER, PR and HER-2 in canine mammary tumors. 3,3'-diaminobenzidine chromogen. Scale bar, $20 \mu \mathrm{m}$. ER positive and/or PR positive and HER-2 negative signals are associated with the phenotype Luminal A. ER positive and/or PR positive and HER-2 positive signals are associated with the phenotype Luminal B. The phenotype HER-2 upregulated was characterized by ER negative, PR negative and HER-2 positive signals. ER negative, PR negative, and HER-2 negative signals are associated with the triple negative phenotype. (B) Photomicrograph of (B-a) negative human breast cancer control and (B-b) negative to low protein expression of ER, PR, HER-2 and E-cadherin in canine mammary cancer. (B-c) Human samples positive for ER, PR, HER-2 and E-cadherin. Magnification, x40. Laboratory of Molecular Investigation of Cancer (LIMC), 2019. ER, estrogen receptor; PR, progesterone receptor; HER-2, human epidermal growth factor receptor.

pulmonary metastasis, and there were no secondary complications associated with mammary cancer detected in the remaining three dogs. In the triple-negative tumor phenotype, the mean survival time associated with this profile was 274 days. A total of three dogs (3/17) did not exhibit evidence of disease complications, and 14 died from lung and/or liver metastasis. The survival curve of each phenotype is presented in Fig. $2(\mathrm{P}<0.0001)$.

Low E-cadherin expression is associated with poor prognostic outcome. Positive E-cadherin expression was observed in $80 \%(n=84)$ of mammary tumors, whereas no staining was observed in $20 \%$ ( $\mathrm{n}=21)$ of samples. Regarding the E-cadherin intensity, it was observed that 15 mammary tumors were scored as ' + ', 52 samples were scored as ' ++ ' and 17 samples were scored as ' +++ '.

The present study also compared the level of E-cadherin expression with the assessed phenotypic groups. A significant association was observed between the intensity of expression among the four profiles considered $(\mathrm{P}=0.03)$. The majority of samples with luminal A and B phenotypes presented a score of ' ++ ' and ' +++ '. On the other hand, tumors classified as HER-2 positive and triple-negative primarily presented scores of ' 0 ', '+' and '++' (Table III). 
Table I. Antibodies and dilutions.

\begin{tabular}{llccc}
\hline Antibody & \multicolumn{1}{c}{ Specificity } & Clone & Dilution & Supplier \\
\hline E-cadherin & (Mouse) & $36 /$ Ecad & $1: 2,000$ & BD Biosciences \\
ER & Monoclonal (mouse) & 1 D5 & $1: 150$ & Santa Cruz Biotechnology, Inc. \\
PR & Monoclonal (rabbit) & SP42 & $1: 400$ & Abcam \\
HER-2/neu & Polyclonal (rabbit) & C18 & $1: 800$ & Santa Cruz Biotechnology, Inc.
\end{tabular}

ER, estrogen receptor; PR, progesterone receptor; HER-2, human epidermal growth factor receptor 2.

Table II. Distribution of frequency of clinicopathological characteristics in the mammary cancer phenotypes of female dogs.

\begin{tabular}{|c|c|c|c|c|}
\hline Clinical characteristics & Luminal A, $\mathrm{n}$ & Luminal B, $\mathrm{n}$ & HER-2 positive, $n$ & Triple-negative, $\mathrm{n}$ \\
\hline No complications & 36 & 32 & 2 & 4 \\
\hline Recurrence & 1 & 2 & 0 & 0 \\
\hline \multicolumn{5}{|l|}{ Metastasis } \\
\hline Cutaneous & 2 & 0 & 1 & 0 \\
\hline Lung & 3 & 5 & 7 & 12 \\
\hline Liver & 0 & 2 & 0 & 1 \\
\hline \multicolumn{5}{|l|}{ TNM } \\
\hline I & 15 & 20 & 1 & 3 \\
\hline II & 10 & 10 & 2 & 4 \\
\hline III & 8 & 2 & 4 & 4 \\
\hline IV & 5 & 6 & 1 & 1 \\
\hline $\mathrm{V}$ & 3 & 1 & 0 & 4 \\
\hline Uninformed & 1 & 2 & 2 & 1 \\
\hline
\end{tabular}

TNM, Tumor-Node-Metastasis; HER-2, human epidermal growth factor receptor 2.

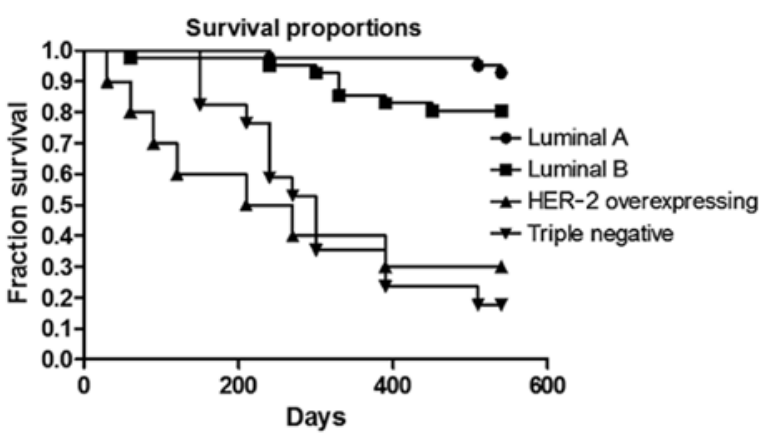

Figure 2. Kaplan-Meier survival curves representing the different phenotypes in canine mammary tumor samples. Log-rank test $(\mathrm{P}<0.001)$. HER-2, human epidermal growth factor receptor.

\section{Discussion}

Previous studies have demonstrated that canine mammary cancer is a heterogeneous disease $(24,26,51)$. Despite previous studies have tried to define histopathological classifications able to associating the type of mammary tumors and prognostic features, these attempts have failed in a number of ways; particularly in predicting disease characteristics in the early stages, in the monitoring of progress, and in the assessment of risk of recurrence and mortality in the absence of treatment $(10,40,41)$.
The present study suggested that histopathological classification are not associated with a clear prognosis. It was observed that the same histopathological subtype may exhibit different phenotypes and, as a result, different outcomes. Therefore, it has been suggested that the anatomical and morphological evaluation of neoplastic lesions should not be considered as the only diagnostic method. In veterinary medicine, few studies investigated molecular classifications in combination with the immunohistochemical markers in canine mammary tumors $(25,26,51)$. In addition, there are discrepancies between previous studies, which are based on a variety of markers and different techniques, making challenging to perform comparisons among previous methodologies $(24-26,51,52)$. Notably, the main limitation of the present study was the non-standardization of the subtype and the histological grade of the neoplasms used.

Therefore, the classification proposed in the present study was based on four immunohistochemical markers (ER, PR, HER-2 and E-cadherin) that were used to define the following phenotypic groups: i) luminal A; ii) luminal B; iii) HER-2 positive; and iv) triple-negative. The use of these markers proved to be very effective in defining the phenotypic profiles of canine mammary tumors to ensure an accurate association with prognosis. This is the main result of the present study, as 
Table III. Distribution of frequency of intensity of E-cadherin expression in canine mammary tumors according to each phenotype.

\begin{tabular}{lcccc}
\hline Immunostaining & Luminal A, $\mathrm{n}$ & Luminal B, $\mathrm{n}$ & HER-2 positive, $\mathrm{n}$ & Triple-negative, $\mathrm{n}$ \\
\hline Negative & 6 & 5 & 4 & 7 \\
Weak & 5 & 4 & 3 & 3 \\
Moderate & 23 & 22 & 2 & 5 \\
Strong & 6 & 9 & 0 & 1 \\
Total & 40 & 40 & 9 & 16 \\
\hline
\end{tabular}

HER-2, human epidermal growth factor receptor 2.

phenotypic classifications from previous studies use additional markers to define the panel $(25,26,51)$.

Collectively, it was observed that the majority of canine neoplasms were classified as luminal A and luminal B, which suggested a favorable prognosis. These groups were characterized by positive expression of ERs and PRs. It has already been previously established that elevated expression levels of these receptors occurs in normal mammary glands and benign mammary tumors (3). However, mammary cancer can also exhibit expression of these receptors, which tends to have an improved prognosis while the negative staining is associated with the most malignant mammary tumors $(24,52,53)$.

ERs are steroid receptors located in the cytoplasm and on the nuclear membrane $(54,55)$. The activation of cytoplasmic steroidal receptors occurs via the non-genomic pathway (56). Non-genomic effects do not depend on gene transcription or protein synthesis and involve steroid-induced modulation of cytoplasmic regulatory proteins or cell membrane boundaries $(57,58)$. Previous studies have demonstrated that the activation of this pathway influences mammary gland carcinogenesis and disease progression (59-61).

There are few studies in veterinary literature that investigated the presence and actions of ER and PR in cytoplasmic in mammary tumors $(62,63)$. These studies revealed important information about the heterogeneity of this cancer. However, none of these focused on the prognostic value of these findings in mammary cancer. Rutteman et al (62) measured cytoplasmic ERs and PRs in normal and neoplastic mammary tissues of bitches. Rutteman et al (62) concluded that the expression of these receptors was more frequent in normal and benign neoplasm samples. Due to the results observed, they also concluded that metastases were less frequently observed in those with the same receptors. Donnay et al (63) demonstrated that poorly differentiated malignant tumors in bitches express lower concentrations of ER and PR in the cytoplasm when compared with healthy glands. Donnay et al suggested that the expression of ER and PR are greater in the most differentiated tumors and with less aggressive biological behavior. In addition, other studies (64-66) have evaluated nuclear immunoexpression of these same receptors, ER and RP, and yet the findings corroborate the results of Rutterman et al (62) and Donay et al (63).

The expression of the HER-2 protein was demonstrated to be an efficient prognostic marker $(22,24,67)$. In the present study, there was an increased mortality rate in the luminal B group compared with the luminal A. HER-2 positive phenotype, defined by the absence of ER and PR, as well as the HER-2 expression, exhibited the worst prognosis compared with the other groups. The expression of HER-2 protein in canine mammary tumors was determined by Dutra et al (68) and the results are in line with the present study, as they demonstrated that upregulation of the HER-2 protein is associated with more aggressive neoplasms. However, Campos et al (69) observed no prognostic features associated with this marker.

In the present study, it was observed that triple-negative tumors are associated with a shorter survival time and, therefore, a worse prognosis. Kim et al (52) demonstrated that $18.7 \%$ of canine mammary tumors analyzed were triple-negative, and that the triple-negative phenotype was associated with a poor prognosis.

Other molecular classifications based on immunohistochemical markers for mammary tumors in female dogs were described in three previous studies. Gama et al (26) investigated an immunohistochemical panel based on five markers (ER, PR, HER-2, CK5, p63 and P-cadherin) and determined five phenotypes: Luminal A, luminal B, HER-2 positive, basal-like and null phenotype. In line with the present study, there was a significant difference between the groups regarding the prognosis and survival time, except for in the null phenotype. Sassi et al (25) proposed five immunohistochemical markers for classifying neoplasms in the luminal A, luminal B, HER-2 positive, basal-like and typical-like phenotypes. However, they only identified the luminal A subtype, luminal B and basal-like phenotypes. In contrast with the present study, there were no statistically significant differences in survival times between phenotypes (25). Im et al (51) used six antibodies (ER, HER-2, CK-14, P63, smooth muscle actin and vimentin) to define six groups: Luminal A, luminal B, HER-2 positive, basal-like and typical-like. Im et al (51) suggested that low ER expression and upregulation of HER-2 were associated with poor prognosis in canine mammary tumors.

The addition of the E-cadherin antibody to the panel ensures the classification of neoplastic cells in the epithelial profile. The association of this marker with the other groups allows the evaluation of the different behaviors among neoplasms characterized in the same phenotypic subtype. The present study demonstrated that the absence or low expression of E-cadherin was associated with more aggressive and metastatic phenotypes (triple-negative and HER-2 positive) representing an important marker that can 
help to understand and better define the development and/or progression of the disease. Poorly differentiated, invasive and metastatic canine mammary carcinomas exhibited a loss of E-cadherin expression in certain tumor cell subpopulations, suggesting that altered E-cadherin expression may be an important process in malignant transformation. This hypothesis is supported by the observation that the loss of E-cadherin expression is associated with a shorter overall survival time and disease-free period (70).

Previous studies have demonstrated that the decrease in E-cadherin expression is associated with tumors of a higher invasive grade, and therefore more metastatic $(13,43)$, in line with the results of the present study. The present study also observed that the absence or low expression of E-cadherin was found associated with more aggressive and metastatic phenotypes (triple-negative and HER-2 positive).

The proposed classification based on the phenotypic subtypes luminal A, luminal B, HER-2 positive and triple-negative was performed using immunohistochemical markers (ER, PR, HER-2 and E-cadherin), and proved to be an important prognostic tool for malignant canine mammary tumors. The classification described in the present study could be used in the field of oncology to provide valuable information about the course and evolution of mammary tumors in canine species. Notably, the main limitation of the present study was the non-standardization of the subtype and the histological grade of the neoplasms used.

\section{Acknowledgements}

The authors would like to thank Mrs Georgia Modé Magalhães (Federal Institute of the South of Minas, Muzambinho, MG, Brazil) and Mr Felipe Augusto Ruiz Sueiro (VETPAT, Campinas, SP, Brazil) for their technical support.

\section{Funding}

The present study was supported by the Conselho Nacional Científico e Tecnológico (grant no. 140624/2013) and Fundação de Apoio à Pesquisa e Extensão de São José do Rio Preto (grant no. 208/2014).

\section{Availability of data and materials}

The datasets used during the present study are available from the corresponding author upon reasonable request.

\section{Authors' contributions}

DAPDCZ conceived and designed the study. GRV performed the experiments and wrote the paper. JRL translated the main text of the article into the English language. GBG, MGM, JRL, ABDN and MTC recruited the patients and collected the samples. LBMS and RMR performed the immunohistochemistry assays. DAPDCZ revised and edited the manuscript.

\section{Ethics approval and consent to participate}

The Ethics Committee on Animal Experimentation of the Faculty of Medicine of São José do Rio Preto (approval no. 3231/2012) approved the present study on August 16, 2012. The Committee for Ethics in Research on Human Beings of the Faculty of Medicine of São José do Rio Preto granted the use of the human tissues.

\section{Patient consent for publication}

Not applicable.

\section{Competing interests}

The authors declare that they have no competing interests.

\section{References}

1. Egenvall A, Bonnett BN, Ohagen P, Olson P, Hedhammar A and Von Euler H: Incidence of and survival after mammary tumors in a population of over 80,000 insured female dogs in Sweden from 1995 to 2002. Prev Vet Med 69: 109-127, 2005.

2. Lana SE, Rutteman GR and Withrow SJ: Tumors of the mammary gland. In: Small Animal Clinical Oncology. 4th edition. Withrow SJ and MacEwen EG (eds.) WB Saunders, Missouri, pp619-633, 2007.

3. Sorenmo KU, Worley DR and Goldschmidt MH: Tumors of the mammary gland. In: Small Animal Clinical Oncology. 5th edition. Withrow SJ, Vail DM and Page RL (eds.) Elsevier, Missouri, pp537-556, 2013.

4. De Nardi AB, Raposo-Ferreira TMM and da Assunção KA: Neoplasias Mamárias. In: Oncologia em Cães e Gatos. 2nd edition. Daleck CR and De Nardi AB (eds.) Editora Roca, Rio de Janeiro, pp726-756, 2016.

5. Sleeckx N, de Rooster H, Veldhuis Kroeze EJ, van Ginneken C and van Brantegem L: Canine mammary tumours, an overview. Reprod Domest Anim 46: 1112-1131, 2011.

6. Brody RS, Goldschimidt MA and Rosze J: Canine mammary gland neoplasia. J Am Anim Hosp Assoc 19: 61-90, 1985.

7. Al Dissi AN, Haines DM, Singh B and Kidney BA: Immunohistochemical expression of vascular endothelial growth factor and vascular endothelial growth factor receptor-2 in canine simple mammary gland adenocarcinomas. Can Vet J 5: 1109-1114, 2010

8. Oliveira Filho JC, Kommers GD, Masuda EK, Marques MF, Fighera RA, Irigoyen LF and Barros CL: Estudo restrospectivo de 1.647 tumores mamários em cães. Pesq Vet Bras 30: 177-185, 2010.

9. Feliciano MA, Silva AS, Peixoto RVR, Galera PD and Vicente WR: Estudo clínico, histopatológico e imunoistoquímico de neoplasias mamárias em cadelas. Arq Bras Med Vet Zootec 64: 1094-1100, 2012.

10. Zuccari DA, Pavam MV, Terzian AC, Pereira RS, Ruiz CM and Andrade JC: Immunohistochemical evaluation of e-cadherin, Ki-67 and PCNA in canine mammary neoplasias: Correlation of prognostic factors and clinical outcome. Pesq Vet Bras 28: 208-215, 2008.

11. Manuali E, De Giuseppe A, Feliziani K, Fortes K, Casciari C and Marchesi MC: CA 15-3 cell lines and tissue expression in canine mammary cancer and the correlation between serum levels and tumour histological grade. BMC Vet Res 8: 86, 2012.

12. Cassali GD, Lavalle GE, de Nardi AB, Ferreira E, Bertagnolli AC, Estrela-Lima A, Alessi AC, Daleck CR, Salgado BS, Fernandes CG, et al: Consensus for the diagnosis, prognosis and treatment of canine mammary tumors-2013. Brazilian J Vet Pathol 7: 38-69, 2013.

13. Yoshida K, Yoshida S, Choisunirachon N, Saito $T$ Matsumoto K, Saeki K, Mochizuki M, Nishimura R, Sasaki N and Nakagawa T: The relationship between clinicopathological features and expression of epithelial and mesenchymal markers in spontaneous canine mammary gland tumors. J Vet Med Sci 76: 1321-1327, 2014.

14. Cassali GD, Lavalle GE, De Nardi AB, Ferreira E, Bertagnolli AC, Lima AE, Alessi AC, Daleck CR, Salgado B, Fernandes CG, et al: Consensus for the diagnosis, prognosis and treatment of canine mammary tumors. Brazilian J Vet Pathol 4: 153-180, 2011.

15. Hampe JF and Misdorp W: Tumors and dysplasias of the mammary gland. Bull World Health Organ 50: 111-133, 1974. 
16. Monlux AW, Roszel JF, Macvean DW and Palmer TW: Classification of epithelial canine mammary tumours in a defined population. Vet Pathol 14: 194-217, 1977.

17. Misdorp W: Histologic classification and further characterization of tumors in domestic animals. Adv Vet Sci Comp Med 20 191-221, 1976.

18. Goldschmidt M, Peña L, Rasotto R and Zappulli V: Classification and grading of canine mammary tumors. Vet Pathol 48: 117-131, 2011.

19. Zaha DC: Significance of immunohistochemistry in breast cancer. World J Clin Oncol 5: 382-392, 2014.

20. Blows FM, Driver KE, Schmidt MK, Broeks A, van Leeuwen FE, Wesseling J, Cheang MC, Gelmon K, Nielsen TO, Blomqvist C, et al: Subtyping of breast cancer by immunohistochemistry to investigate a relationship between subtype and short and long term survival: A collaborative analysis of data for 10,159 cases from 12 studies. PLoS Med 7: e1000279, 2010.

21. Dai X, Xiang L, Li T and Bai Z: Cancer hallmarks, biomarkers and breast cancer molecular subtypes. J Cancer 7: 1281-1294, 2016.

22. Perou CM, Sørlie T, Eisen MB, van de Rijn M, Jeffrey SS, Rees CA, Pollack JR, Ross DT, Johnsen H, Akslen LA, et al: Molecular portraits of human breast tumours. Nature 406 : 747-752, 2000

23. Perou CM and Børresen-Dale AL: Systems biology and genomics of breast cancer. Cold Spring Harb Perspect Biol 3: a003293, 2011

24. Peña L, Gama A, Goldschmidt MH, Abadie J, Benazzi C, Castagnaro M, Díez L, Gärtner F, Hellmén E, Kiupel M, et al: Canine mammary tumors: A review and consensus of standard guidelines on epithelial and myoepithelial phenotype markers, HER2, and hormone receptor assessment using immunohistochemistry. Vet Pathol 51: 127-145, 2014.

25. Sassi F, Benazzi C, Castellani G and Sarli G: Molecular-based tumour subtypes of canine mammary carcinomas assessed by immunohistochemistry. BMC Vet Res 6: 5, 2010.

26. Gama A, Alves A and Schmitt F: Identification of molecular phenotypes in canine mammary carcinomas with clinica implications: Application of the human classification. Virchows Arch 453: 123-132, 2008

27. Sorlie T, Perou CM, Tibshirani R, Aas T, Geisler S, Johnsen H, Hastie T, Eisen MB, van de Rijn M, Jeffrey SS, et al: Gene expression patterns of breast carcinomas distinguish tumor subclasses with clinical implications. Proc Natl Acad Sci USA 98: 10869-10874, 2001

28. Cirqueira MB, Moreira MARM, Soares LR and Freitas-Júnior R: Subtipos moleculares do câncer de mama. Femina 39: 499-503, 2011.

29. Prat A,Parker JS, Karginova O,Fan C,Livasy C, Herschkowitz JI, $\mathrm{He} \mathrm{X}$ and Perou CM: Phenotypic and molecular characterization of the claudin-low intrinsic subtype of breast cancer. Breast Cancer Res 12: R68, 2010.

30. Meisel JL, Venur VA, Gnant M and Carey L: Evolution of targeted therapy in breast cancer: Where precision medicine began. Am Soc Clin Oncol Educ Book 38: 78-86, 2018.

31. Rivenbark AG, O'Connor SM and Coleman WB: Molecular and cellular heterogeneity in breast cancer: Challenges for personalized medicine. Am J Pathol 183: 1113-1124, 2013.

32. Ignatiadis $\mathbf{M}$ and Sotiriou C: Luminal breast cancer: From biology to treatment. Nat Rev Clin Oncol 10: 494-506, 2013.

33. Arteaga CL, Sliwkowski MX, Osborne CK, Perez EA, Puglisi F and Gianni L: Treatment of HER2-positive breast cancer: Current status and future perspectives. Nat Rev Clin Oncol 9: 16-32, 2011.

34. Fabi A, Malaguti P, Vari S and Cognetti F: First-line therapy in HER 2 positive metastatic breast cancer: Is the mosaic fully completed or are we missing additional pieces? J Exp Clin Cancer Res 35: 104, 2016.

35. Figueroa-Magalhães MC, Jelovac D, Connolly R and Wolff AC: Treatment of HER2-positive Breast Cancer. Breast 23: 128-136, 2014.

36. Mendes D, Alves C, Afonso N, Cardoso F, Passos-Coelho JL, Costa L, Andrade S and Batel-Marques F: The benefit of HER2-targeted therapies on overall survival of patients with metastatic HER2-positive breast cancer-a systematic review. Breast Cancer Res 17: 140, 2015.

37. Sharma P: Biology and management of patients with triple-negative breast cancer. Oncologist 21: 1050-1062, 2016.

38. Lebert JM, Lester R, Powell E, Seal M and McCarthy J: Advances in the systemic treatment of triple-negative breast cancer. Curr Oncol 25 (Suppl 1): S142-S150, 2018.
39. Vieira DS, Dufloth RM, Schmitt FC and Zeferino LC: Breast cancer: New concepts in classification. Rev Bras Ginecol Obstet 30: 42-47, 2008 (In Portuguese).

40. Braunstein LZ and Taghian AG: Molecular phenotype, multigene assays, and the locoregional management of breast cancer. Semin Radiat Oncol 26: 9-16, 2016.

41. Chan KK, Matchett KB, McEnhill PM, Dakir el H, McMullin MF, El-Tanani Y, Patterson L, Faheem A, Rudland PS, McCarron PA and El-Tanani M: Protein deregulation associated with breast cancer metastasis. Cytokine Growth Factor Rev 26: 415-423, 2015.

42. Baranwal S and Alahari SK: Molecular mechanisms controlling E-cadherin expression in breast cancer. Biochem Biophys Res Commun 384: 6-11, 2009.

43. Matos AJ, Lopes C, Carvalheira J, Santos M, Rutteman GR and Gärtner F: E-cadherin expression in canine malignant mammary tumours: Relationship to other Clinico-pathological variables. J Comp Pathol 134: 182-189, 2006.

44. Sorenmo K: Canine mammary gland tumors. Vet Clin North Am Small Anim Pract 33: 573-596, 2003.

45. Owen LN: TNM Classification of Tumours in Domestic Animals World Health Organization, Geneva, pp53, 1980.

46. Lopes JR, Maschio LB, Jardim-Perassi BV, Moschetta MG, FerreiraLC,Martins GR, Gelaleti GB and De Campos ZuccariDA: Evaluation of melatonin treatment in primary culture of canine mammary tumors. Oncol Rep 33: 311-319, 2015.

47. Lopes J, Arnosti D, Trosko JE, Tai MH and Zuccari D: Melatonin decreases estrogen receptor binding to estrogen response elements sites on the OCT4 gene in human breast cancer stem cells. Genes Cancer 7: 209-217, 2016.

48. Allred DC, Harvey JM, Berardo M and Clark GM: Prognostic and predictive factors in breast cancer by immunohistochemical analysis. Mod Pathol 11: 155-168, 1998.

49. Koeppen HK, Wright BD, Burt AD, Quirke P, McNicol AM, Dybdal NO, Sliwkowski MX and Hillan KJ: Overexpression of HER2/neu in solid tumours: An immunohistochimical survey. Histopathology 38: 96-104, 2001.

50. Remmele W and Stegner HE: Overexpression of HER2/neu in solid tumours: An immunohistochimical survey. Pathologe 8: 138-140, 1987.

51. Im KS, Kim NH, Lim HY, Kim HW, Shin JI and Sur JH Analysis of a new histological and molecular-based classification of canine mammary neoplasia. Vet Pathol 51: 549-559, 2014.

52. Kim NH, Lim HY, Im KS, Kim JH and Sur JH: Identification of Triple-negative and Basal-like canine mammary carcinomas using four basal markers. J Comp Pathol 148: 298-306, 2013

53. de las Mulas JM, Millán Y and Dios R: A prospective analysis of immunohistochemically determined estrogen receptor alpha and progesterone receptor expression and host and tumor factors as predictors of disease-free period in mammary tumors of the dog. Vet Pathol 42: 200-212, 2005.

54. Hewitt SC and Korach KS: Estrogen receptors: New directions in the new millennium. Endocr Rev 39: 664-675, 2018.

55. Fuentes N and Silveyra P: Estrogen receptor signaling mechanisms. Adv Protein Chem Struct Biol 116: 135-170, 2019.

56. Fox EM, Andrade J and Shupnik MA: Novel actions of estrogen to promote proliferation: Integration of cytoplasmic and nuclear pathways. Steroids 74: 622-627, 2009.

57. Boonyaratanakornkit V, Hamilton N, Márquez-Garbán DC, Pateetin P, McGowan EM and Pietras RJ: Extranuclear signaling by sex steroid receptors and clinical implications in breast cancer. Mol Cell Endocrinol 466: 51-72, 2018.

58. Vrtačnik P, Ostanek B, Mencej-Bedrač $S$ and Marc J: The many faces of estrogen signaling. Biochem Med (Zagreb) 24: 329-342, 2014.

59. Cortez V, Mann M, Brann DW and Vadlamudi RK: Extranuclear signaling by estrogen: Role in breast cancer progression and metastasis. Minerva Ginecol 62: 573-583, 2010.

60. Marino M, Galluzzo P and Ascenzi P: Estrogen signaling multiple pathways to impact gene transcription. Curr Genomics 7: 497-508, 2006

61. Poulard C, Treilleux I, Lavergne E, Bouchekioua-Bouzaghou K, Goddard-Léon S, Chabaud S, Trédan O, Corbo L and Le Romancer M: Activation of rapid oestrogen signalling in aggressive human breast cancers. EMBO Mol Med 4: 1200-1213, 2012.

62. Rutteman GR, Misdorp W, Misdorp W, Blankenstein MA and van den Brom WE: Oestrogen (ER) and progestin receptors (PR) in mammary tissue of the female dog: Different receptor profile in non-malignant and malignant states. Br J Cancer 58: 594-599, 1988 . 
63. Donnay I, Rauis J, Devleeschouwer N, Wouters-Ballman P, Leclercq $G$ and Verstegen J: Comparison of estrogen and progesterone receptor expression in normal and tumor mammary tissues from dogs. Am J Vet Res 56: 1188-1194, 1995.

64. Peña L, Perez-Alenza MD, Rodriguez-Bertos A and Nieto A: Canine inflammatory mammary carcinoma: Histopathology, immunohistochemistry and clinical implications of 21 cases Breast Cancer Res Treat 78: 141-148, 2003.

65. Millanta F, Calandrella M, Bari G, Niccolini M, Vannozzi I and Poli A: Comparison of steroid receptor expression in normal, dysplastic, and neoplastic canine and feline mammary tissues. Res Vet Sci 79: 225-232, 2005.

66. Chang CC, Tsai MH, Liao JW, Chan JP, Wong ML and Chang SC: Evaluation of hormone receptor expression for use in predicting survival of female dogs with malignant mammary gland tumors. J Am Vet Med Assoc 235: 391-396, 2009.

67. Sorlie T, Tibshirani R, Parker J, Hastie T, Marron JS, Nobel A, Deng S, Johnsen H, Pesich R, Geisler S, et al: Repeated observation of breast tumor subtypes in independent gene expression data sets. Proc Natl Acad Sci USA 100: 8418-8423, 2003.
68. Dutra AP, Granja NV, Schmitt FC and Cassali GD: c-erbB-2 expression and nuclear pleomorphism in canine mammary tumors. Brazilian J Med Biol Res 37: 1673-1681, 2004.

69. Campos LC, Silva JO, Santos FS, Araújo MR, Lavalle GE, Ferreira E and Cassali GD: Prognostic significance of tissue and serum HER2 and MUC1 in canine mammary cancer. J Vet Diagn Invest 27: 531-535, 2015.

70. Klopfleisch R, von Euler H, Sarli G, Pinho SS, Gärtner F and Gruber AD: Molecular carcinogenesis of canine mammary tumors: News from an old disease. Vet Pathol Online 48: 98-116, 2011.

(c) (i) () $)$ This work is licensed under a Creative Commons Attribution-NonCommercial-NoDerivatives 4.0 International (CC BY-NC-ND 4.0) License. 